\title{
OS TEMPLOS DE MATRIZ AFRICANA EM SALVADOR E O MEIO AMBIENTE URBANO
}

\author{
THE AFRICAN MATRIX TEMPLES IN SALVADOR AND THE URBAN \\ ENVIRONMENT
}

${ }^{1}$ Bruno Moitinho Andrade de Souza

\begin{abstract}
RESUMO
O presente trabalho se destina a analisar a relação entre os Templos de Matriz Africana e o Meio Ambiente nos seus aspectos artificiais. Aprofundará a análise de perspectivas históricas dos terreiros e a formação desses locais sagrados com o desenvolvimento da cidade, especificamente em Salvador. Examinará o atual panorama do Povo de Santo na capital baiana. Os terreiros são pontos de resistência da herança africana, fazem parte da história e cultura da sociedade brasileira. Os templos afro-brasileiros estão inseridos no contexto das cidades e o ordenamento urbano deve observar a existência dos terreiros e suas dinâmicas sociais urbanas.
\end{abstract}

Palavras-chave: Meio ambiente, Artificial, Candomblé, Cultura, Cidade

\begin{abstract}
This study is intended to examine the relationship between the African Matrix Temples and Environment in its artificial aspects. Deepen the analysis of histical perspectives of religious communities and the formation of these sacred sites with the development of the city, specifically in Salvador. Examine the current situation of the Holy People of the Bahian capital. The terreiros are of African heritage resistance points, are part of the history and culture of Brazilian society. The temples are within the context of cities and urban planning must note the existence of religious communities and their urban social dynamics.
\end{abstract}

Keywords: Environment, Artificial, Candomble, Culture, City

\footnotetext{
${ }^{1}$ Mestrando em Direito pela Universidade Federal da Bahia - UFBA, Bahia (Brasil). Diretor Jurídico na Associação Baiana de Defesa do Consumidor - ABDECON, Bahia (Brasil). E-mail: moitinhobr@gmail.com
} 


\section{INTRODUÇÃO}

A existência das religiões de matriz africana no Brasil é incontestável, pois ela está presente em todo território nacional. Especificamente na Bahia, a sua influência é ainda mais evidente. Por fazer parte da sociedade, o Direito não fica alheio a essas manifestações.

O presente trabalho pretende analisar o Candomblé a partir da ótica do Meio Ambiente Artificial, fazendo um estudo sobre Templos de Matriz Africana no Estado da Bahia, em especial, Salvador.

A hipótese é que, em geral, os terreiros são espaços comunitários que assumem uma importância histórica e cultural na cidade de Salvador, e pelo fato de estarem inseridos no contexto urbano, merecem ser protegidos pelo Direito Urbanístico.

Para cumprir o seu propósito, a pesquisa explorará o acervo bibliográfico que trata dos assuntos envoltos ao tema. Utilizar-se-ão livros de juristas reconhecidos nacionalmente, e de autores de outras áreas, fora do Direito. Ademais, o presente trabalho buscará referências em dissertações e teses que tratam de pesquisas e estudos sobre os templos religiosos negros.

O método de abordagem eleito para o desenvolvimento deste trabalho é o caminho hipotético-dedutivo, por meio de pesquisa bibliográfica teoria jurídica nacional, notadamente, nos ramos do Direito Ambiental, Antropologia, História e Urbanismo.

Pela necessidade de recorte temático e a limitação em nível monográfico, não serão abordadas as questões fundiárias e do trabalho das comunidades por merecer maior aprofundamento em âmbito dissertativo.

Ao longo do trabalho, será aprofundado o estudo sobre o Candomblé, especificamente, os templos mais antigos, optando-se por não tratar sobre a Umbanda, religião que é genuinamente nacional e relevante no Brasil e surgiu no final do século XIX e início do século $\mathrm{XX}$, mas que se diferencia do Candomblé, pois traz outros elementos da tradição africana, notadamente a Angola, além da tradição indígena e da Doutrina Espírita.

Inicialmente será abordado o conceito de Meio Ambiente Artificial. Em seguida, o terreiro será analisado como comunidade histórico-social, a origem dos terreiros no Brasil e na Bahia, e apontar o panorama atual dos templos em Salvador. Por fim, será relacionado o povo de santo com o meio ambiente artificial. 


\section{MEIO AMBIENTE ARTIFICIAL}

O Meio Ambiente é um conceito que vem sendo construído ao longo dos tempos. O ser humano desde os primórdios vem utilizando e explorando o meio em que vive e os seus recursos. Considera-se que o Meio Ambiente é único, mas que pode ser analisado a partir de pontos de perspectivas. Em geral, didaticamente, o Meio Ambiente pode ser dividido em quatro tipos: Natural, Cultural, Laboral, e Artificial, sendo este último, foco da presente análise.

O meio ambiente artificial é aquele que foi alterado e constituído pelo ser humano ao longo da história. Pode ser entendido como um conceito por exclusão, sob o qual se elimina o que é do ambiente cultural, o do trabalho e o natural. Faz parte desse espaço, o complexo de edificações urbanas de âmbito público ou privado, à luz de Anderson Furlan da Silva (2010, p. 27).

A diferença principal entre o artificial e cultural é que nem todo local urbano é revestido de valores culturais. Os seus atributos se destacam nesse meio por trazer relevante significado histórico, artístico e/ou arqueológico. Em face disso, o meio ambiente artificial é visto sob a ótica do ordenamento urbano, em sua complexidade da vida social, tal como as questões de transporte público e outros aspectos urbanísticos. No entanto, há situações que envolvem tanto as questões culturais quanto as de caráter propriamente urbano.

Na Constituição Federal, a questão urbana está imersa na política de desenvolvimento urbano de competência do Município para a garantia do bem-estar dos seus habitantes (artigo 182). O plano diretor, por exemplo, é um instrumento basilar urbano obrigatório para municípios de mais de 20 mil habitantes, estando regulado na Lei 10.257/2001, também chamada de Estatuto da Cidade.

O Estatuto da Cidade estabelece que a função social de uma propriedade urbana será cumprida quando esta se adequa às exigências fundamentais de ordenação contidas em Plano Diretor, "assegurando o atendimento das necessidades dos cidadãos quanto à qualidade de vida, à justiça social e ao desenvolvimento das atividades econômicas" (art. 39 do Estatuto da Cidade).

Paulo Affonso Leme Machado (2015, 446) conceitua o Plano Diretor como:

Plano diretor é um conjunto de normas obrigatórias, elaborado por lei municipal específica, integrando o processo de planejamento municipal, que regula as atividades e os empreendimentos do próprio Poder Público Municipal e das pessoas físicas ou jurídicas, de Direito Privado ou Público, a serem levados a efeito no território municipal. 
O plano diretor não é o único instrumento de planejamento urbano previsto em lei. Existem, por exemplo, os programas e projetos setoriais e os planos econômicos e sociais, entre outros contidos no rol não taxativo do artigo $4^{\circ}$ da citada legislação urbanística.

Nesse contexto, a política urbana deve ser norteada por diretrizes, consideradas por Paulo de Bessa Antunes (2010, p. 321) como princípios que têm como objetivo o desenvolvimento das cidades e suas funções sociais. Pode-se destacar, dentre alguns, "proteção, preservação e recuperação do meio ambiente natural e construído, do patrimônio cultural, histórico, artístico, paisagístico e arqueológico" (artigo $2^{\circ}$, inciso XII da referida Lei).

Isso demostra que, no planejamento urbano municipal, a gestão pública dos espaços urbanos não deve ignorar as questões ambientais, seja natural seja o do patrimônio cultural. A própria Constituição estabelece como uma das competências municipais a promoção da proteção do patrimônio histórico-cultural local (art. 30, IX). Para Machado (2015, p. 461), “o Município não pode deixar a proteção dos bens e valores históricos e culturais sediados em seu território somente para a ação federal e estadual”.

O Plano Diretor deve ser elaborado sob o aspecto da sustentabilidade do ordenamento urbano, observando as peculiaridades dos locais, e proteção dos espaços mais vulneráveis, criando uma esfera de função socioambiental da propriedade urbana.

Em janeiro de 2015, foi instituído o Estatuto da Metrópole, Lei 13.089/15, estabelecendo diretrizes para o planejamento e gestão de regiões metropolitanas e aglomerações urbanas instituídas pelos Estados, e estabelecendo casos de improbidade administrativa relacionados ao não cumprimento da Lei. Com o crescimento das cidades e o avanço do desenvolvimento urbano, em vários pontos do país, se fez necessário um planejamento que não ficasse restrito aos limites dos municípios, mas que seja integrado às regiões metropolitanas.

Nesse interim, o citado Estatuto prevê o plano de desenvolvimento urbano integrado de região metropolitana ou aglomeração urbana, abrangendo não apenas as regiões urbanas, mas as rurais. Faz parte do conteúdo mínimo desse plano: a delimitação das áreas com restrições à urbanização visando à proteção do patrimônio ambiental ou cultural, bem como das áreas sujeitas a controle especial pelo risco de desastres naturais, se existirem (art. 12, $1^{\circ}$, V).

Essa legislação é uma tentativa de suprir uma lacuna sobre o planejamento urbano que encontra dificuldade em face à concentração populacional, às questões que ultrapassam o 
município e desarticulação entre os poderes públicos municipais vizinhos, a exemplo do esgotamento sanitário e situações de ameaça a patrimônio natural e cultural que necessitem de atuação conjunta dos entes públicos.

\section{ORIGEM DOS TERREIROS}

Durante o século XVI ao século XIX, pessoas nascidas no continente africano, pertencentes a grupos étnicos e culturais distintos, foram vendidas e "exportadas" para o Brasil como mercadorias escravas. Podem-se identificar os bantos das regiões que atualmente se denominam Angola, Congo, Guiné, Moçambique e Zaire; os Fons do Benim; e os Iorubas da Nigéria, de cidades como Ketu, Ondô, Ijkexá, Oyó e Abeokuta (os Égbas). Esses homens e mulheres africanos, considerados como bichos e sem valor humano pelos colonizadores, trouxeram bagagem de milênios de culturas e religiosidades, que ao se reorganizarem no solo brasileiro, deu-se a gênese do Candomblé.

A escravidão construída como base do edifício social da Grécia e da Roma Antiga serviu de inspiração para o colonialismo-escravista iniciada século $\mathrm{XV}$, e se tornou durante séculos a principal fonte lucrativa. $\mathrm{O}$ negro, antes livre, passou a ser considerado como categoria de semoventes, tais como bois e cavalos, sendo imposto a ele a perda da sua humanidade (LUZ, 2013, p. 171). Estima-se segundo Regiane Augusto de Mattos (2012, p. 65-66), que no século XVI, o total de negros escravizados e comercializados no Atlântico foi de 800 mil a 1,3 milhão. Já nos séculos XVII e XVIII, foram mais de sete milhões de escravos na exportação, somente no século XVIII, 60 mil africanos foram enviados às Américas. Essa previsão representa milhões de escravos africanos que foram expulsos de suas terras.

Luiz Cláudio Nascimento (2010, p. 22) aborda quatro ciclos do tráfico negreiro: o primeiro, ciclo Guiné, corresponde ao século XVI; o segundo, ciclo de Angola e Congo, ocorrido no século XVII; o terceiro, o ciclo de Mina, ocorrera nos três primeiros quartos do século XVIII; e o quarto, o ciclo da Baía de Benin, no período de 1770 a 1850.

Elikia M’Bokolo (2009) em seus estudos sobre a história das civilizações da África negra, cujo início se confunde com a própria história do homem, aprofunda mais a análise do tráfico negreiro e suas consequências aos futuros países do continente africano. Sobre o comércio dos negros destinados às Américas, ela afirma que:

[...] organizou-se como um autêntico sistema, orquestrado pelos Estados europeus. Se os efeitos do tráfico dos negros sobre as economias europeias são ainda controversos e se as consequências sobre as sociedades africanas continuam a 


\begin{abstract}
alimentar os debates mais apaixonados, não há a menor dúvida que, antes de se tornar no século XIX, "o comércio vergonhoso" quase unanimemente condenado, foi durante três séculos um gigantesco e frutuoso negócio que mobilizou a Europa inteira e não poupou nenhuma região da África. Se os europeus foram os instigadores desta empresa, foi essencialmente para o Novo Mundo que o comércio de negros transportou os africanos arrancados à sua terra, sendo as exportações para a Europa inteiramente marginais durante todo o período do tráfico, quer legal, quer clandestino. (M'BOKOLO, 2009, p. 273).
\end{abstract}

Os escravocratas tentaram impor a desafricanização do africano escravo, porque "a identidade africana representava o vínculo à terra, à ancestralidade, à religião, à liberdade, e, sobretudo, à soberania sobre a própria vida" (NASCIMENTO e NASCIMENTO, 2008, p. 138). A exploração não se restringia apenas ao corpo do escravo, mas voltava-se para alijamento dos valores ancestrais e tradicionais africanos. Nas palavras de Elizabete Umbelino de Barros (2007, p. 09), os negros tinham "suas práticas rituais ligadas à família, à aldeia, ao clã ou ao reino e diziam respeito, sobretudo à coletividade".

Ainda na África, o processo de dominação física e psicológica forçava o abandono de práticas de séculos pela destruição de locais de culto, de estruturas sociais das comunidades. No Brasil, houve um choque cultural em um sistema de modelo patriarcal e escravocrata. Uma sociedade que não permitira que o escravo exercesse sua identidade, rejeitando-se o valor humano e a 'coisificar' o indivíduo.

Segundo Marco Aurélio Luz (2013), o discurso do 'perigo' e risco de 'africanização' no Brasil, impôs o término do "tráfico e o início das políticas de imigração de brancos, etnocídio, genocídio, através da filosofia do 'embranquecimento'; ao mesmo tempo que se reprimia de todas as formas possíveis os valores civilizatórios negros" (LUZ, 2013, p. 145).

Paralelamente ao aumento da migração europeia aumentando a população branca no Brasil, os negros eram mandados para frente de batalha no evento que foi denominado como Guerra do Paraguai, ajudando no aceleramento do processo de branqueamento da população:

\footnotetext{
Se a imigração de europeus visava aumentar a população branca, a guerra do Paraguai proporcionou uma ocasião propícia para diminuir o número de negros. Convocados a pulso ou seduzidos pela obtenção da carta de alforria, foi convocada uma enorme quantidade de negros para a guerra. A maioria dos condecorados como Voluntários da Pátria eram senhores que sequer estiveram na guerra, mas simplesmente cederam dez ou mais escravos para o combate. A proporção dos convocados era de aproximadamente 40 negros para um branco.(LUZ, 2013, p. 177)
}

No processo histórico, o povo negro resistiu sob diversas formas e contextos contra a opressão colonialista da escravidão. A formação dos milhares de quilombos ou mocambos pelo Brasil, "próximas aos engenhos, às minas de ouro e pedras preciosas, nos sertões e nos 
campos” (MATTOS, 2012, p. 137), revela-se como símbolo de resistência e luta pela libertação.

O quilombo do Palmares é um significativo exemplo, porque durante mais de um século, constituiu-se em um vasto território assumindo dimensão de reino africano e abrigando não apenas a população negra, mas, também, a indígena e branca insatisfeita com as questões políticas e econômicas da Coroa (LUZ, 2013, p. 292). Conforme explicita MATTOS (2012, p. 144):

\footnotetext{
Em Palmares, havia uma complexa estrutura de organização com ruas, casas, muros, capelas, oficinas de fundição, produção de cerâmica e utensílios em madeira, lavouras de feijão, milho, mandioca e cana-de-açúcar. Era formado por várias aldeias, com seus respectivos chefes. Todas as aldeias eram comandadas por uma comunidade principal, onde ficava o líder do quilombo.
}

As Irmandades negras foram instituições criadas como legado civilizatório africano com objetivo não apenas de luta pela libertação da escravidão, mas, também, pela “ocupação de um espaço-social urbano capaz de garantir a coesão grupo necessária à afirmação existencial, a constituição da identidade e a continuidade dos valores culturais negros em nossa terra" (LUZ, 2013, p. 293). Vale ressaltar que no início da formação do Candomblé no Brasil, houve proibição dos ritos tanto pelos senhores escravocratas e quanto de autoridades da Igreja Católica. Uma forma encontrada para contornar essa dificuldade foi o sincretismo, o culto às deidades africanas juntamente com as divindades católicas.

Portanto, essas Irmandades ajudaram na associação dos santos católicos com as divindades dos orixás e pode-se citar a relação com o Senhor do Bonfim - Jesus Cristo - a Oxalá; Santo Antônio como Ogun; São Jorge como Oxóssi; São Lázaro como Omolu ou Obaluaiyê; São Jerônimo como Xangố; Santa Barbara como Iansã.

Essa associação simbólica caracterizando "africanização nagô do catolicismo" (LUZ, 2013, p. 332) viabilizou as manifestações religiosas tradicionais nos espaços da sociedade, até mesmo no ambiente interno das igrejas e que se mantem até os dias atuais. A Lavagem do Bonfim, festa popular baiana na qual há um ritual de limpeza e lavagem das escadarias da Igreja do Nosso Senhor do Bonfim é associado ao festival religioso de matriz africana denominado Águas de Oxalá, e a procissão baiana da Nossa Senhora de Conceição da Praia foi associada ao ritual de Oxum; o caruru de Santa Barbara e seus festejos homenageando a santa, são exemplos desse sincretismo religioso contemporâneo.

O surgimento e formação dos templos do Candomblé foram propiciados pelas Irmandades negras que cultivavam valores africanos. Marco Aurélio Luz (2013) cita como um 
importante exemplo, o da Irmandade de Nossa Senhora da Boa Morte da Barroquinha que se reuniam as "altas sacerdotisas do culto nagô, encabeçadas pela Iya Nassô, zeladora do culto à Sango no afin, palácio real, que fundam o Ilê Asé Airá Intilé, considerado a primeira casa de culto aos orixás no Brasil” (LUZ, 2013, p. 332).

Além dessas instituições, importante mencionar o surgimento do movimento de negros islamizados, os Malês, que se insurgiram no século XIX contra a escravidão e outras formas de exploração, mas que foram reprimidos de maneira violenta. Eles consideravam como entidade religiosa máxima o Olorumulua, uma associação entre Olorum, orixá supremo, e o Alá, o Deus dos Mulçumanos (LUZ, 2013, p. 339). Esse sincretismo acomodava as crenças Iorubás com as do Alcorão.

Mesmo após o término oficial da escravidão no Brasil e o significativo crescimento do número de terreiros (SANTOS, 2009, p. 65), não raras vezes, as práticas de herança africana eram coibidas de maneira violenta. O povo de terreiro sofreu todo tipo de agressões por parte da população e instituições públicas, como a Polícia, e a Igreja:

\begin{abstract}
Alvo de perseguições policiais e religiosas, as casas de candomblé, no passado, eram invadidas, tendo seus objetos sagrados quebrados e as vezes, até apreendidos. Vários terreiros eram fechados, babalorixás e iyalorixás levados presos. Era uma religião que muitos denominavam de "seita demoníacas", devido à perseguição que lhe fazia a Igreja Católica, que se valia de seu poder para também obrigar os negros a serem catequisados, no intuito de afastá-los de sua religião. (OXAGUIÃ e KILEUY, 2014, p. 34).
\end{abstract}

O Código Criminal do Império de 1830, por exemplo, determinava como crime, art. 276: "Celebrar em casa, ou edifício, que tenha alguma forma exterior de Templo, ou publicamente em qualquer lugar, o culto de outra Religião, que não seja a do Estado".

Não apenas a perseguição dos terreiros pelo Poder Policial da época, a exemplo da Delegacia de Jogos e Costumes, mas a imprensa fez um papel relevante no discurso contra os costumes de base africana. Edmar Ferreira Santos (2009) ao examinar a perseguição e resistência no Recôncavo da Bahia identifica o Jornal "A Ordem” na cidade de Cachoeira, nas primeiras décadas do século XX. Este jornal publicava reportagens e 'denúncias' contra o que ele sustentou como 'perturbadores da tranquilidade e ordem pública', e a liturgia religiosa dos terreiros com suas danças e músicas, denominada pela imprensa como 'batuques', que 'afrontavam' a família e a sociedade.

Esse jornal local, em específico, se dedicava a campanha de intolerância exigindo que a polícia reprimisse os espaços negros, locais que considerava como 'degenerados' e de 'africanismo barato'. É importante destacar que a imprensa relatava que existiam autoridades 
policiais que protegiam e participavam das atividades dessa comunidade tradicional, apesar de a polícia ter sido um expressivo agente de repressão, conforme já relatado (SANTOS, 2009, p. 53-63 e 135). Paralelamente a isso, no mesmo período, houve o surgimento de casas de candomblés que vieram a consolidarem-se como terreiros mais antigos (OLIVEIRA, 2007, p. 48).

Pode-se afirmar que na história da resistência desse povo tradicional, foram três etapas consideradas nas tensões do lugar (SERRA, 2006 apud SERENSEN, 2015, p. 26): a primeira, até 1930, foi o período quando o Estado colocava o Candomblé no patamar de caso de polícia; a segunda, iniciada em 1930 e consolidada em 1950 é a utilização do Candomblé como algo folclórico pelo Poder Público, apesar de a perseguição policial não ter se extinguido; e a terceira é a que começa na década de 80 quando houve o início de reconhecimento do valor histórico e cultural do candomblé, e a gênese de fato de iniciativas de preservação pelos instrumentos jurídicos.

Apenas na década de 1930, na assinatura pelo presidente Getúlio Vargas do Decreto Lei n. 1202 foi a termo a proibição legal da prática dos cultos afro-brasileiros. Segundo Sorensen (2015, p. 28), a promulgação do decreto é "geralmente atribuída pela tradição oral do povo de santo à mãe de santo Aninha do Ilê Axé Opó Afonjá. Segundo consta, a ialorixá teria influenciado Vargas por intermédio do ministro Osvaldo Aranha, seu filho de santo".

No entanto, na Bahia, mesmo com o fim da proibição, até a década de 1970, os terreiros precisavam pedir autorização e pagar uma taxa à polícia para o seu funcionamento. Foi tão somente com a Lei estadual n. 3097/72 que a autorização foi dispensada, pois os terreiros foram considerados como "sociedades afro-brasileiras para atos folclóricos" (anexo da citada Lei).

Apesar da política contra os templos de matriz africana, eles resistiram e, atualmente, persistem na preservação da sua cultura, herança e linguagem. As principais nações que formaram o Candomblé no Brasil foram a bantu, a iorubá ou nagô (nesse conceito está inserido nações que cultuam os orixás como o Ketu, Ijexá, Efan, Egbado e Egba) e a fon ou jeje. Usa-se o termo 'nação' para traduzir os países, cidades e etnias africanas com aspectos culturais específicos. A religiosidade da nação bantu tem como divindades os inquices, a nação ioruba, os orixás e a ancestralidade e, a nação fon, os voduns. Apesar de semelhanças entre as nações citadas, elas diferem entre si pela ritualidade, pelas formas de danças, musicalidade, alimentação e vestimentas (OXAGUIÃ; KILEUY, 2014, p. 36-37). 


\section{MAPEAMENTO DOS TERREIROS EM SALVADOR}

Um importante projeto foi desenvolvido pela Prefeitura de Salvador e outras entidades públicas e privadas para o conhecimento do atual panorama dos Templos negros em Salvador. O Projeto de Mapeamento dos Terreiros de Candomblé de Salvador foi realizado nos anos de 2006 e 2007 e publicado em 2008. Identificaram-se 1.296 (mil, duzentos e noventa e seis) templos na cidade. A maior quantidade de terreiros está nos bairros do subúrbio, como o bairro Plataforma (57 templos), seguida de Paripe (40 templos). Existe uma quantidade relevante de terreiros em áreas contíguas no bairro de Cajazeiras XI e isso reflete no fato de que nas três últimas décadas, pelo menos 677 terreiros foram criados.

Por isso, sobre a antiguidade desses milhares de terreiros espalhados pela capital do estado da Bahia, 68,6\% tem menos de 31 anos de existência. A grande quantidade de templos se concentra na Região Administrativa XVII que corresponde à região mais populosa da cidade e a metade tem $360 \mathrm{~m}^{2}$ de área de terreiro. Jocelino Teles dos Santos (2008) ao analisar os dados do mapeamento em tela, faz a seguinte reflexão:

\footnotetext{
O elevado crescimento do número de terreiros nessas áreas demonstra que, nas últimas décadas, havia a possibilidade do povo-de-santo encontrar terrenos extensos em um ambiente ecológico adequado para a consecução de rituais, festas públicas e "assentamento" das entidades" (SANTOS, 2008, p. 08)
}

A cor de pele da maioria da maioria dos líderes é negra, 59,1\% seguida de parda, 31, $6 \%$, branca, $4,6 \%$, indígena, $2,7 \%$ e amarela, $0,8 \%$. Quanto ao sexo, a maioria é mulher, $63,7 \%$ (SANTOS, 2008, p. 19). Nesse universo afro-brasileiro é predominantemente dominado pelas mulheres negras, e nesses espaços religiosos as Mães de Santo reinam, representando a força feminina de resistência.

\section{POVO DE SANTO E O MEIO AMBIENTE URBANO}

As contribuições do povo africano na formação da nação brasileira são expressivas e, especificamente na formação das cidades baianas, a influência negra é ainda mais forte. $\mathrm{O}$ desenvolvimento dos espaços sagrados do Candomblé nas cidades faz parte da história da capital baiana e da região do Recôncavo. As comunidades negras foram obrigadas a resignificarem suas tradições acompanhando o processo de urbanização das cidades.

O terreiro, então, é um local sagrado e está inserido no processo de urbanização de cidades como Salvador. Nesses locais, apresentam-se a paisagem cultural do Brasil e são 
"marcas urbanas" na medida em que foram "vetores de agregação habitacional" (ABADIA, 2010, p. 50). O Candomblé é “uma religião urbana, e a manutenção de espaços amplos vem se tornando cada vez mais difícil, devido à crescente pressão populacional” (BARROS, 2014, p. 23). Esses templos em Salvador que antes estavam localizados nas regiões consideradas periféricas, hoje, com o avanço da cidade, fazem parte do perímetro urbano. Bairros populares de Salvador surgiram a partir de locais de terreiros pelo desenvolvimento da urbanização da capital baiana.

Por isso, pode-se que afirmar que a ocupação dos terreiros nos espaços urbanos "teve um relevante papel no processo de formação urbana de Salvador, porque contribuiu para o surgimento de vários bairros populares da cidade, como o Curuzu, Engenho Velho da Federação e Mata Escura" (SOUZA, SANTOS e SOUSA, 2015, 420).

Segundo Luz (2013. p. 320), "no início do século passado, os africanos originários do Golfo de Benin, incluindo as etnias Jeje (Ewe), Nagô (Yorubá), Haussá, Tapa e benin, dentre outras, formam aproximadamente metade da população africana em Salvador”. O mesmo autor afirma que Salvador era rodeada de quilombos cujos locais serviam para reuniões da comunidade negra e celebração da religiosidade africana (LUZ, 2013, p. 325). O processo de urbanização de vários pontos da capital baiana foi reflexo da reconstrução da identidade da África nas terras brasileiras.

\footnotetext{
A herança cultural e religiosa trazida da África legou aos negros modelos e valores à formação dos candomblés, que foram sendo alterados, incorporando novas estruturas, adaptando-os à realidade social-urbana de Salvador. Alguns terreiros são verdadeiros pedaços da África, mas é importante ressaltar que cada um tem sua identidade particular por conta do seu processo histórico-cultural, dos seus adeptos praticantes e das suas divindades cultuadas, refletindo assim na dinâmica de utilização do espaço sagrado. (SOUZA, SANTOS e SOUSA, 2015, 420).
}

O processo de expansão da cidade de Salvador objetivou apenas as necessidades econômicas e industriais. As áreas verdes foram “substituídas por 'próteses de concreto', antagônicas às estruturas preexistentes - vasta áreas verdes e grandes representantes da Mata Atlântica" (CONCEIÇÃO, 2008, p. 35). A população que tinha menos condições financeiras foi forçada a ocupar áreas marginais que, em geral, eram distantes não apresentavam infraestruturas suficientes à demanda social.

Os terreiros estavam localizados nas regiões mais afastadas do centro das cidades, no início do século passado não tinham os equipamentos públicos urbanísticos imprescindíveis, tal como a energia elétrica, o saneamento o básico e transporte. Com o tempo, ao se atrair cada vez mais filhos de santo, que começaram a residir nas regiões próximas às casas de culto 
e passaram a exigir melhores condições e melhorias para a localidade (OLIVEIRA, 2007, p. 87).

\begin{abstract}
A forte ligação dos cultos afro-brasileiros com elementos da natureza, notadamente a mata e a água contribuíram para a implantação de candomblés nas arrebaldes da cidade que, nas primeiras décadas do século XX tinham um caráter predominantemente rural, embora não se deva esquecer das condições financeiras dessas pessoas, que sempre buscavam terras mais baratas para a implantação de seus terreiros. (OLIVEIRA, 2007, p. 81).
\end{abstract}

Vale destacar que terreiros instalados próximos às regiões mais urbanizadas tiveram que se deslocar para áreas marginais pela intolerância religiosa representada pela atuação da polícia, como afirma Sueli Conceição (2008, p. 37): “a repressão da polícia contra as práticas religiosas também foi uma das causas que provocaram o deslocamento dos terreiros".

A influência dos terreiros na configuração da cidade de Salvador, também, pode ser percebida na denominação dos logradouros, mesmo que não oficialmente reconhecidos, conforme Iris Verena de Oliveira (2007) sustenta:

\begin{abstract}
Assim é que os nomes das ruas registraram práticas culturais ou personagens ilustres a ela relacionadas, evidenciando, ao longo da história, a atuação e a presença de afro-descendentes em Salvador. Com este mesmo sentido de marca da presença na cidade são encontrados lugares como a Rua dos Nagôs, Ladeira de Nanã, Ogunjá, Bonocó ou Cabula, topônimos que constituem indícios dos significados atribuídos aos espaços da cidade pelos adeptos das religiões afro-brasileiras, em decorrência de suas paradas e andanças em ruas, becos e ladeiras da antiga cidade de Salvador. (OLIVEIRA, 2007, p. 91-92).
\end{abstract}

Portanto, não restam dúvidas, que a formação de bairros populares soteropolitanos se confunde, muitas vezes, com a fundação e instalação dos terreiros. Essa afirmação encontra respaldo quando se analisa a história de bairros e terreiros como (CONCEIÇÃO, 2008): o bairro Cabula e o Terreiro Ilê Axé Opô Afonjá; o bairro Trobogy e o Terreiro Olga Ngunza Za Nkisi Dandelunda Ye Tempo; Estrada Velha do Aeroporto e o Terreiro Manso Dandalungua Cocuazenza; bairro da Federação e o Terreiro Oxumarê; bairro da Liberdade e o Terreiro Vodum Zo; Bairro San Martin e o Terreiro Manso Dandalunda Neto.

Os espaços do Candomblé não são homogêneos. Em determinados dias, o "território sagrado se estende pelos espaços públicos como nas situações de cortejos e procissões, quando as ruas se revestem de uma aura sagrada durante o período que dura o ritual; ao término deste, o local volta a sua função profana” (ZAMBUZZI, 2010, p. 20). Os locais públicos urbanos podem se tornar sagrado por alguns momentos, ao longo de certos rituais, como o oferecimento dos ebós (oferendas) nas encruzilhadas, ruas, canteiros, praças e jardins. 
Esse fato se dá pela carência cada vez maior de espaços disponíveis para o exercício do sagrado no além-muro das comunidades de povo de santo.

Os espaços da comunidade são de interação de compromisso político-social, pois ampliam-se para o além-muros dos terreiros e atuam nas vizinhanças por movimentos educacionais e sociais. Há nesses locais, conforme Elizabete Barros (2007, p. 47), um estímulo para o exercício da cidadania. Os terreiros são locais de resistência e afirmação do povo de santo, e neles, sob a perspectiva do seu território interacional, “o que se busca no espaço religioso não é o território físico, mas sim o político" (CONCEIÇÃO, 2008, p. 39). O terreiro é tido como uma das principais formas sociais do negro no Brasil (CONCEIÇÃO, 2008, p. 30).

O terreiro tem papel social relevante que influe no seu entorno, ajudando na vizinhança através de ações sociais, chegando a ser identificado cursos profissionalizantes e até mesmo curso pré-vestibular fornecido no interior de um terreiro. Conceição (2008, p. 104) afirma que:

\footnotetext{
Quanto às atividades realizadas com as comunidades, mais de $30 \%$ dos terreiros desenvolvem atividades sociais, políticas e culturais como creches, distribuição de cestas básicas, cursos variados (capoeira, ioruba, dança afro, bordado, teatro, manicure, artesanato), palestras, programas na área de saúde, doação de alimentos e de brinquedos para as crianças, e há terreiros que têm info centro.
}

Os terreiros são locais de acolhimento de filhos de santo, seja como moradia temporária no processo do ritual ou quando os filhos precisam de um local para residirem. Isso agrega ao fato de que o Candomblé é um fato social que "extrapola os espaços físicos da cidade e possui toda uma dinâmica social muito particular que precisa ter sua existência garantida" (ZAMBUZZI, 2010, p. 89).

O Candomblé faz parte da história da formação da cidade de Salvador e está inserido nos processos urbanos atuais.

\section{CONSIDERAÇÕES FINAIS}

O presente trabalho revelou a existência do nexo entre a cidade de Salvador - meio ambiente artificial - e o Candomblé como religião urbana. O desenvolvimento dos espaços sagrados de matriz africana faz parte da história da capital baiana, estando inserido no processo de urbanização da cidade. 
Se antes, os terreiros estavam localizados nas regiões afastadas do centro, com o avanço da cidade, passaram a fazem parte do território urbano e da dinâmica social. Estudar a história do povo de santo é apontar a história da formação urbana de Salvador. O Candomblé permanece vivo ao longo de todo o território da cidade, como polo de resistência e perpetuação da cultura afro-brasileira.

Além disso, os espaços do povo de santo não se restringem aos limites restritos dos terreiros. Em determinadas épocas do ano, o território sagrado dos terreiros se estende pelos espaços públicos, como, por exemplo, nos eventos dos cortejos e procissões, momentos nos quais as ruas se revestem por uma aura sagrada enquanto durar o ritual, e voltando a função profana após o término. As encruzilhadas, ruas, canteiros, praças e jardins podem se tornar momentaneamente sagrados ao processo do ritual no oferecimento das oferendas.

Ademais, no espaço social, o terreiro influencia o seu entorno, auxiliando a vizinhança através de cursos, palestras, distribuições de cestas básicas, programas da área da saúde, creches, entre outros, além ser um local de acolhimento dos filhos de santos.

Portanto, na aplicação do Direito e seus instrumentos jurídicos na cidade, deve-se observar a realidade do Candomblé no seu contexto histórico, cultural e urbano.

\section{REFERÊNCIAS}

ABADIA, Lilia. A identidade e o patrimônio negro no Brasil. 2010, 113 p. Dissertação (Mestrado em Ciências da Cultura). Universidade de Lisboa. Lisboa, 2010.

ALBUQUERQUE, Newton; CARMO, Valter (org). Diálogo ambiental, constitucional e internacional. Fortaleza: Premius, 2013.

ALMEIDA, Jorge Luis Sacramento. Ensino/aprendizado dos alabôs: uma experiência nos terrieiros ilê axê oxumarê e zoogodô bogum malê rundó. 2009, 279 f. Tese (Doutorado em Música) - Universidade Federal da Bahia. Salvador, 2009.

ANTUNES, Paulo de Bessa. Direito Ambiental. 12 ed. Rio de Janeiro: Lúmen Juris, 2010. BELTRÃO, Antônio. Curso de direito ambiental. São Paulo: Método, 2009.

BARROS, Elizabete Umbelino de. Línguas e Linguagens nos candomblés de nação angola. 2007, 295 f. Tese (Doutorado em Linguística e Semiótica) - Universidade de São Paulo, 2007.

BARROS, José Flávio Pessoa de. A floresta sagrada de Ossaim: o segredo das folhas. Rio de Janeiro: Pallas, 2014. 
CAULA, Bleine; MARTINS, Dayse; ALBUQUERQUE, Newton; CARMO, Valter (org). Diálogo ambiental, constitucional e internacional. Fortaleza: Premius, 2013.

CHAUI, Marilena. Cultura e democracia. São Paulo: Cortez, 1997.

CONCEIÇÃO, Sueli Santos. O processo de urbanização como imperativo da reestruturação espacial e liturgia das religiões de matriz africana. 2008, 133 p. Dissertação (Mestrado em Estudos Étnicos e Africanos) - Universidade Federal da Bahia. Salvador, 2008.

CUNHA FILHO, Francisco Humberto; COSTA, Rodrigo Vieria. Direitos Culturais: definição, abrangência e doutrina in CAULA, Bleine; MARTINS, Dayse et al. Diálogo ambiental, constitucional e internacional. Fortaleza: 2013.

FERNANDES, Mariana Balen. Território quilombola e o estado: etnicidade, direitos coletivos e processos de licenciamento ambiental e identificação territorial. In: ROCHA, Julio Cesar de Sá da; SERRA, Ordep (org). Direito ambiental, conflitos socioambientais e comunidades tradicionais. Salvador: Edufba, 2015.

FIGUEREDO, Guilherme José Purvin de. Curso de Direito Ambiental. $4^{\mathrm{a}}$ ed, rev. atual. e ampl. São Paulo: Revista dos Tribunais, 2011.

GOMES, Carla Amado. Direito Ambiental: o ambiente como objeto e os objetos do direito do ambiente. Curitiba: Juruá, 2010.

GUERRA, Sidney; GERRA, Sérgio. Direito Ambiental. Rio de Janeiro: Freitas Bastos, 2005 .

LARA, Larissa Michelle. As danças do sagrado no profano, transpondo tempos e espaços em rituais de candomblé. 1999, 220 f. Dissertação (Mestrado em Educação Física) Universidade Estadual de Campinas. Campinas, 1999.

LINDOSO, Dirceu. A razão quilombola: estudos em torno do conceito quilombola de nação etnográfica. Organização por Bruno Cézar Calvalcanti. Maceió: Edufal, 2011.

LITTLE, Paul E. Territórios sociais e povos tradicionais no Brasil: por uma antropologia da territorialidade. Brasília: DAN/UnB. 2002. (Série Antropologia, 322). Disponível em: $<$ http://vsites.unb.br/ics/dan/Serie322empdf.pdf $>$. Acessado em 01/12/2015.

LUZ, Marco Aurélio. Agadá: dinâmica da civilização africano-brasileira. 3 ed. Salvador: Edufba, 2013.

MACHADO, Paulo Affonso Leme. Direito ambiental brasileiro. 22 ed. rev. amp. atual. São Paulo: Malheiros, 2015.

MATTOS, Regiane Augusto. História e cultura afro-brasileira. São Paulo: Contexto, 2012.

M'BOKOLO, Elikia. África negra: história e civilizações. Trad. Alfedro Margarido. Rev. acad. Daniela Moreau e Valdemir Zamparoni. Salvador: Edufba, 2009. 
MELO, Naurelice Maia de. Territorialidade e saber ambiental: água e mata como elementos sagrados na Represa do Prata. 2010, 130 p. Dissertação (Mestrado em Desenvolvimento Regional e Urbano da Universidade Salvador) - Universidade Salvador. Salvador, 2010.

MILARÉ, Édis. Direito do Ambiente: a gestão ambiental em foco: doutrina, jurisprudência, glossário. 7 ed. rev. atual. e reform. São Paulo: Revista dos Tribunais, 2011.

NASCIMENTO, Gizêlda Melo do; NASCIMENTO, Elisa Larkin. Reflexões sobre "descobrimento" das américas. In: NASCIMENTO, Elisa Larkin. A matriz africana no mundo. São Paulo: Selo negro, 2008.

NASCIMENTO, Luiz Cláudio. Bitedô: onde moram os nagôs. Rio de Janeiro: Ceap, 2010.

OLIVEIRA, Iris Verena Santos de. Becos, ladeiras e encruzilhadas: andanças do povo de santo pela cidade de salvador. 2007, 204 p. Dissertação (Mestrado em História Social) Universidade Federal do Ceará, 2007.

OXAGUIÃ, Vera de; KILEUY, Odé. O candomblé bem explicado: nações bantu, ioruba e fon. Organização por Marcelo Barros. Rio de Janeiro: Pallas, 2014.

PENA, Rodolfo Ferreira Alves. As múltiplas espacialidades contextuais do candomblé: estudos de geografia de religião. 2014, 128 f. Dissertação (Mestrado em Geografia) Universidade Federal do Paraná. Curitiba, 2014.

ROCHA, Julio Cesar de Sá da. Direito, grupos étnicos e etnicidade: reflexões sobre o conteúdo normativo de povos e comunidades tradicionais. In: ROCHA, Julio Cesar de Sá da; SERRA, Ordep (org). Direito ambiental, conflitos socioambientais e comunidades tradicionais. Salvador: Edufba, 2015.

RODRIGUES, José Eduardo Ramos. Tutela do patrimônio ambiental cultural. In: PHILIPPI JUNIOR, Arlindo; ALVES, Alaôr Caffé. Curso Interdisciplinar de direito Ambiental. São Paulo: Manole, 2005.

SANTANA FILHO, Diosmar M.; GERMANI, Guiomar Inez. A população negra no Estado: relação espaço e tempo. In: ROCHA, Julio Cesar de Sá da; SERRA, Ordep (org). Direito ambiental, conflitos socioambientais e comunidades tradicionais. Salvador: Edufba, 2015.

SANTOS, Edmar Ferreira. O poder dos candomblés: perseguição e resistência no recôncavo da bahia. Salvador: Edufba, 2009.

SANTOS, Jocelino Teles dos. Os candomblés da bahia no século XXI. Disponível em: <http://www.terreiros.ceao.ufba.br/pdf/Os_candombles_no_seculo_XXI.pdf.>. Acessado em $01 / 12 / 2015$.

SERRA, Ordep. Os olhos negros do brasil. Salvador: Edufba, 2014.

SILVA, Anderson Furlan da. Direito Ambiental. Rio de Janeiro: Forense, 2010.

SILVA, José Afonso da Silva. Direito ambiental constitucional. São Paulo: Malheiros, 1997. 
SILVA, Julia Alexim da. O direito à cultura na constituição de 1988 in CAULA, Bleine; MARTINS, Dayse; ALBUQUERQUE, Newton; CARMO, Valter (org). Diálogo ambiental, constitucional e internacional. Fortaleza: Premius, 2013.

SIRVINSKAS, Luís Paulo. Manual de direito ambiental. 9 ed. rev., atual e ampl. São Paulo: Saraiva, 2011.

SOUZA, Bruno Moitinho Andrade de; SANTOS, Clarissa Pereira Gunça dos; SOUSA, Sue Safira Andrade de. Os terreiros de candomblé em salvador: a colaboração do tombamento para a preservação do espaço natural. In: ROCHA, Julio Cesar de Sá da; SERRA, Ordep (org). Direito ambiental, conflitos socioambientais e comunidades tradicionais. Salvador: Edufba, 2015.

ZAMBUZZI, Mabel. O espaço material e imaterial do Candomblé na Bahia: o que é e como proteger. 2010, 143 p. Dissertação (Mestrado em Arquitetura e Urbanismo) - Universidade Federal da Bahia. Salvador, 2010. 